6 MONICA Quality Control Centre for Event Registration. MONICA memo 57. Dundee: Ninewells Hospital, 1985.

7 Martin CA. Hobbs MST, Armstrong BK. Measuring the incidence of acut myocardial infarction: the problem of possible acute myocardial infarction. Acta Med Scand 1988;suppl 728:40-7.

8 Statistics and Epidemiological Research Corporation. EPIC epidemiological computer package. Seattle, Washington: Statistics and Epidemiological Research Corporation, 1987.

9 ISIS-1 (First International Study of Infarct Survival) Collaborative Group. Randomised trial of intravenous atenolol amongst 16,027 cases of suspected acute myocardial infarction: ISIS-1. Lancet 1986;ii:57-66.

10 Yusuf S, Sleight P, Rossi PRF, et al. Reduction in infarct size, arrhythmias, chest pain and morbidity by early intravenous beta-blockade in suspected acute myocardial infarction. Circulation 1983;67:32-41.

11 MIAMI Trial Research Group. Metoprolol in acute myocardial infarction (MIAMI). A randomized placebo-controlled trial (with discussants). Eur Heart f 1985; 6:199-226.

12 Göteborg Metoprolol Trial. Effects on mortality and morbidity in acute myocardial infarction. Circulation 1983;67 suppl I):26-32.
13 Pedersen TR. The Norwegian multicenter study of timolol after myocardial infarction. Circulation 1983;67 (suppl I):49-53.

14 Goldstein S. Propranolol therapy in patients with acute myocardial infarction: the beta-blocker heart attack trial. Circulation 1983;67(suppl I):53-7.

15 Thompson PL, Hobbs MST, Martin CA. The rise and fall of ischaemic heart disease in Australia. Aust $N Z$ Z Med 1988;18:327-37.

16 Peter T, Norris RM, Clarke MB, et al. Reduction in enzyme levels by propranolol after acute myocardial infarction. Circulation 1978;57:1091-5.

17 Norris RM, Sammel NL, Clarke ED, Brandt PWP. Treatment of acut myocardial infarction with propranolol. Further studies on enzyme appear ance and subsequent left ventricular function in treated and control patient with developing infarcts. Br Heart $\mathcal{F}$ 1980;43:617-22.

18 Jurgensen SJ, Frederiksen J, Hansen DA, Sen-Bjergorrd DP. Limitation of myocardial infarct size in patients less than 66 years treated with alprenolol. Br Heart F 1981; 45:583-8

(Accepted 30 October 1989 )

\title{
Individual variation between general practitioners in labelling of hypertension
}

\author{
T D W Smith, D Clayton
}

\begin{abstract}
Variation in labelling of hypertension by individual general practitioners was studied during a continuous opportunistic screening progamme for hypertension in a single general practice with 12 principals. All the general practitioners agreed to label as hypertensive patients with systolic pressures of $\geqslant 200 \mathrm{~mm} \mathrm{Hg}$ or diastolic pressures of $\geqslant 110 \mathrm{~mm} \mathrm{Hg}$ on three consecutive readings. The overall number of patients labelled hypertensive at the beginning of the screening programme was 505 and this rose to 801 after five years. There was a large variation in the numbers of patients recorded as hypertensive at the start of the screening period, with numbers ranging from eight to 112 for individual practitioners. The variation persisted during the screening period, with the numbers of patients detected by individual general practitioners ranging from four to 46 . The average systolic and diastolic pressures recorded among these patients also varied between doctors, and only 24 out of 187 patients had their high pressures recorded on three occasions and so fully met the criteria for diagnosing hypertension.

Clearly, general practitioners are following their own individual criteria in defining hypertension and taking into account factors other than just the measured blood pressure.
\end{abstract}

\section{Introduction}

During the course of a computerised blood pressure screening programme in a large general practice we

Variation among individual general practitioners in their labelling of hypertension during screening period 1983-8: numbers of patients detected and their average blood pressures

\begin{tabular}{|c|c|c|c|c|c|c|c|}
\hline \multirow[b]{2}{*}{ Doctor } & \multicolumn{2}{|c|}{ No $(\%)$ hypertensive in: } & \multirow{2}{*}{$\begin{array}{c}\text { No }(\%) \\
\text { detected } \\
\text { by screening }\end{array}$} & \multicolumn{3}{|c|}{$\begin{array}{l}\text { No (and No treated where different) } \\
\text { with systolic } \geqslant 200 \mathrm{~mm} \mathrm{Hg} \text { and } / \text { or } \\
\text { diastolic } \geqslant 110 \mathrm{~mm} \mathrm{Hg} \text { on: }\end{array}$} & \multirow{2}{*}{$\begin{array}{l}\text { Average systolic and } \\
\text { diastolic pressures of all } \\
\text { patients detected during } \\
\text { screening (mm Hg) }\end{array}$} \\
\hline & 1983 & 1988 & & 3 Readings & 2 Readings & 1 Reading & \\
\hline 1 & $112(22)$ & $126(16)$ & $22(12)$ & 3 & 6 & 13 & $197 / 107$ \\
\hline 2 & $107(21)$ & $160(20)$ & $46(25)$ & $2(1)$ & 12 & $32(28)$ & $185 / 103$ \\
\hline 3 & $53(11)$ & $86(11)$ & $27(15)$ & 6 & $2(1)$ & $19(13)$ & $199 / 110$ \\
\hline 4 & $53(11)$ & $72(9)$ & $12(6)$ & 2 & 3 & 7 & $191 / 109$ \\
\hline 5 & $42(8)$ & $59(7)$ & $22(12)$ & 2 & 3 & $17(14)$ & $178 / 105$ \\
\hline 6 & $31(6)$ & $46(6)$ & $9(5)$ & 0 & 8 & $10)$ & $194 / 108$ \\
\hline 7 & $27(5)$ & $54(7)$ & 158 & 0 & 6 & $9(7)$ & $200 / 105$ \\
\hline 8 & $26(5)$ & $32(4)$ & $6(3)$ & 0 & 2 & $4(3)$ & $173 / 109$ \\
\hline 9 & $20(4)$ & $34(4)$ & $4(2)$ & 3 & 0 & 1 & $206 / 110$ \\
\hline 10 & 14 (3) & 28 (4) & $7(4)$ & 2 & 3 & $2(1)$ & $177 / 116$ \\
\hline 11 & $12(2)$ & $51 \quad 6)$ & $13(7)$ & 3 & 7 & 3 & $193 / 112$ \\
\hline 12 & $8(2)$ & $53(7)$ & $4(2)$ & 1 & 2 & 1 & $195 / 126$ \\
\hline Total & 505 & 801 & 187 & $24(33)$ & $54(53)$ & $109(91)$ & \\
\hline
\end{tabular}

studied the variation among individual general practitioners in their labelling of hypertension.

\section{Methods}

A continuous computerised blood pressure screening programme was undertaken in a large group practice of 12 principals with a list size of about 32000 . Comparison between the individual general practitioners at the start of the screening and after five years was possible as the practice adhered strictly to an individual list system: as far as possible a patient attended the general practitioner he or she was registered with.

All patients aged 40 to 65 years were identified from the age-sex register, and if a normal blood pressure (systolic $\leqslant 160 \mathrm{~mm} \mathrm{Hg}$ and diastolic $\leqslant 100 \mathrm{~mm} \mathrm{Hg}$ ) had not been recorded in their notes within the preceding five years the notes were tagged to alert the general practitioner to measure blood pressure when the patient next attended.

Although there was disagreement over whether to treat mild to moderate levels of raised blood pressure, all the general practitioners agreed that a patient should be labelled hypertensive when three readings of systolic pressure $\geqslant 200 \mathrm{~mm} \mathrm{Hg}$ or diastolic pressure $\geqslant 110 \mathrm{~mm} \mathrm{Hg}$ were recorded. ${ }^{2}$

\section{Results}

From 1983 to 1988 the population to be screened increased by 1856 people through people moving in and out of the practice and age group. The table shows the numbers of patients labelled hypertensive by each general practitioner at the start of the screening programme and after five years of screening.

At the start of screening there were 8800 people aged $40-65$ years. Of these $505(5.7 \%)$ were labelled hypertensive, although the numbers of such patients varied from eight to 112 for individual general practitioners. After five years of screening the total population was 10655 , of whom $801(7 \cdot 5 \%)$ were labelled hypertensive, with numbers for each general practitioner ranging from 28 to 160 . The number of patients labelled hypertensive during the screening period ranged from four to 46.

None of the general practitioners adhered fully to the criteria for labelling hypertension. Of the 187 patients labelled hypertensive during screening only 24 $(12 \cdot 8 \%)$ had had three readings. Overall only $78(42 \%)$ patients had had two or three readings that fulfilled the 
criteria for raised blood pressure. The table also shows the average systolic and diastolic blood pressures at which each doctor decided that a patient had hypertension. These ranged from 173 to $206 \mathrm{~mm} \mathrm{Hg}$ systolic and 103 to $116 \mathrm{~mm} \mathrm{Hg}$ diastolic. In addition, not all patients labelled hypertensive were treated (see table), although most of those not treated had had only one reading that suggested high pressure.

\section{Discussion}

The widespread variation in the labelling of hypertension by the individual general practitioners at the start of the screening programme reflected differing attitudes towards the management of hypertension, and this was largely maintained throughout the screening period.

Although the screening programme seemed to help some doctors in detecting patients with raised blood pressures, most of the doctors who had labelled more of their patients as having raised blood pressure at the start of screening identified more as a result of screening than those who started with fewer. On the other hand, those who identified fewer patients over the five years of screening were more likely to fulfil the agreed criteria. But the low overall proportion of patients detected during the screening period who actually fulfilled the criteria for hypertension $(24 / 187,12 \cdot 8 \%)$ suggests that the general practitioners were unhappy about not treating patients with more borderline blood pressures and perhaps took other factors into consideration. Interestingly, this figure of $12.8 \%$ of patients fulfilling the criteria is very close to the $12.5 \%$ found by Patterson in his study of the diagnosis of hypertension in general practice, in which the same criteria were used. ${ }^{+}$

In conclusion, the results suggest that the screening helped some of the general practitioners to detect patients with significantly raised blood pressure but individual general practitioners seemed to adhere to their own crtieria for labelling hypertension rather than to those formally agreed.

We thank all the partners of the Latham House Medical Practice; Mrs L Drake, medical secretary; Professor M Clarke, professor of community health; Mr John Woods, senior computer officer, Department of Community Health; and Mr A Lewis, medical student.

\section{Australian National Blood Pressure Management Committee. The Australian herapeuric trial in mild hyperension. Lancet 1980;i:1261-7. T \\ 2 Veterans Administration Co-operative Study Group. Effects of treatment on morbidity in hypertension. Results in patients with diastolic blood pressures averaging 115 through $129 \mathrm{mmHg}$. ҰAMA 1967;202:1028-34. \\ 3 Veterans Administration Co-operative Study Group. Effects of treatment on morbidity in hypertension II. Results in patients with diastolic blood pressur averaging 90 through $114 \mathrm{mmHg}$. $7 A M A$ 1970;213:1143-52. \\ 4 Patterson HR. Criteria for the diagnosis of hypertension in general practice. $\exists R$ Coll Gen Pract 1984;34:97-9.}

\title{
Relation between systemic hypertension and sleep hypoxaemia or snoring: analysis in $\mathbf{7 4 8}$ men drawn from general practice
}

\author{
John R Stradling, Joy H Crosby
}

\section{Abstract}

Objective-To establish whether a history of snoring or the degree of overnight hypoxaemia is an important independent predictor of systemic blood pressure.

Design-Prospective community based study of blood pressure in relation to overnight oxygen saturation, height, weight, and a questionnaire assessment of snoring, smoking, and alcohol consumption. Analysis was by multiple linear regression techniques and analysis of variance.

Setting-Small town outside Oxford, served by one group general practice of four partners. All measurements were made at home.

Subjects - The names of 836 men aged 35-65 were drawn at random from the general practitioners' age and sex register and the men then asked to participate; $752(90 \%)$ agreed.

Main outcome measures-Systolic, mean, and diastolic blood pressures and their association with age, obesity, alcohol consumption, cigarette consumption, snoring, and overnight hypoxaemia.

Results-Though systemic blood pressure correlated significantly with overnight hypoxaemia, this was due to the cross correlation with age, obesity, and alcohol consumption. No independent predictive effect of overnight hypoxaemia was found. Snoring was correlated with systemic blood pressure but not significantly so and also was not an independent predictor once age, obesity, and alcohol consumption had been allowed for.

Conclusions - It is unlikely that snoring and sleep hypoxaemia from occult sleep apnoea are important causes of diurnal systemic hypertension when compared with age, obesity, and alcohol consump- tion. The increased prevalence of cardiovascular complications reported in snorers may be due to the confounding variable of obesity or to nocturnal rises in blood pressure that are not reflected in the daytime figures.

\section{Introduction}

In most patients with arterial hypertension there is no apparent cause for the condition, ${ }^{1}$ except that age and body weight are known to be significant partial predictors of actual blood pressure. ${ }^{23}$ Much interest from various sources has been expressed in the possibility that occult sleep apnoea might be the cause of a substantial proportion (25-30\%) of this "essential hypertension." $4-12$ The evidence, however, is conflicting, and two recent studies failed to find an increased prevalence of sleep hypoxaemia in an untreated group of newly diagnosed hypertensive men compared with a matched control group. ${ }^{1314}$ We have looked at 752 men aged 35-65 drawn from one group general practice and compared the power of overnight hypoxaemic episodes and snoring as partial predictors of arterial blood pressure with that of other known predictive factors such as age and obesity.

\section{Subjects and methods}

The town of Wheatley ( $8 \mathrm{~km}$ east of Oxford) is served mainly by one group general practice (four partners). The age and sex register of the practice was used to identify men whose birth dates put them between 35 and 65 years of age at the time of the study. They were then selected for study by year of birth with the year order randomised. Each subject received a 